\title{
WAARHEID EN LEUEN: 'N ETIESE STUDIE
}

\section{INLEIDING}

Dic Psalmeligter sê: alle mense is leucnaars (Ps. 116 : II).

Die Psalmoligter is '

Dus, dic P'salmoligter is 'n Icnenaar.

Maar as dic Psalmeligter " lenenaar is wamecr lo' sô dat alle mense

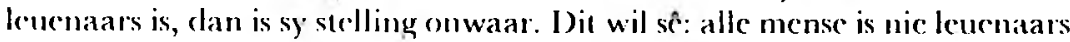
nic.

Hierdie "brain twister" watumee prol. H.C. Stoker met genoce in die jare her sy cerstejaarstudente in die was gebring het, is genocgsance aanduicling dat dit 'n glibberige onderwerp is hierdie.

Nic net glibberig nie maar ook omstrede. Voltaire (angeblat by Thielicke (1968\%, p. 520) he in 'n briel, gedated 21 ()klober i736, aan sy vriend "Thiriot geskerywe: "Dic leuen is 'n euwel net wanneer dit die kwati tot gevolg lact; dit is 'n groot deng wanneer dit die gocie tol stand bring. Dus, wees mece deugsatm as ooit voorlueen. 'n Mens mee lieg soos die duiwel, nic skugerer en nee by gelecutheid nie, maat met vertrone en volgehene. Lieg, my vriend, lieg!"”

In die Afrikaanse l,eflerkumk het fan I,ion-Cachee vroeg al die vraagstuk van watarheid en leuen met sy "l iegrhiwel" aan die orde gestel. Vars soos "n

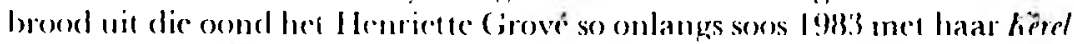

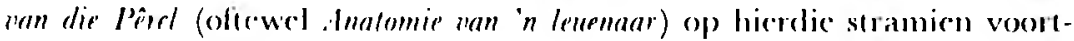
gebordum. Sy, die verefeller in die verhabl, bring die problecm soos volg onder woorde: "Iot hierter het ek vir u ecerlik die waatheid probeer gee. Uit dic aard van clie saak is ny medium woorde. Dis immers 'n storic. Maar noorde, soos et probere aantoon het, is berugte verteiers. Hulle dwing al teen die waarlecid in, en in plaas daarvan om dit bloot te le, verkrag hulle dit. Dat hulle kwansius die werklikheicl sou werespiec̈l. Kaf!" (p. 70, 71). Dat dic vaagstuk van waanhe id en leuen in die woordkuns dic essensic raak, is ná ( irove se aangehaalde woorte seker nie nedig om verder te bewys nic.

Hierdie opsed wil vamuit die Teologiese Etiek 'n verkemning oor dic 
werklikhede van waarheid en leuen doen en dit dan aan die literatore oorlaat om, inclien moontlik, dit vir die woordkuns vrugbaar te maak.

Agtereenvolgens sal aan die orde gestel word:

Die waarheid in (iod geger.

Die watheid deur Satan verwoes.

Dic waarheid in (hristus herstel.

Die wese van die waarlicid.

I)ie wese vall die leuen.

Die soorte lewerns.

Waarheid, feuen cu die woordkuns.

Samevatting.

\section{DIE WAARHEID IN GOD GEGEE}

Teologies beskon st aan die begrip waarheid in die nouste verband mee die wese van (jod. Ben van (Bod se vier wesensname' is lig (1 Joh. 1:15). 1)it beteken dat Hy elie allersuiwerste selfbewuste wese is in wie daar geen duistemis is nic. ( nuder die opskrif (rod is lig behandel Honig (p. 195v.) vier

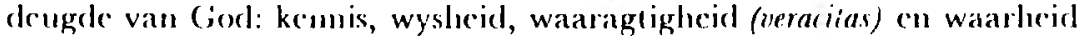
(verilas).

Wat dic waragtigheid van God betref, dit hang saam met dic Hebrecuse woord $\mathrm{em}$. getrouhede, van die werkwoord aman - om vas te maak; (vgl. clie woord "amen" - dil sal waar en seker wees) en die (jrickse woord althinos, wataragtig, wat op lalle plekke in rlie Skrif met (sod in verbaud gel)ring word (bv. Lix. 34:6; Deut. 7:9; P's. 31:6; Joh. 3:33; 17:3; Rom. 3:4).

Met die ueracitas van God word bedoel, dat Hy waarlik God is, die wesenlike God, gecon skyn-Gorl of onegte God nice.

Maar uit die meracilas van God vloci noodwendig sy meritas voont.

$\Lambda 1$ dic gedagtes, woorde, beloftes, bevele, werke van God kan nie anders as louter waarheid wees nie (2Sam. 7:28; Ps. 19:10; 25:10; 33:4; $111: 7$; 119:86; 142, 1.51; I)an. 4:37. Vgl. Bavinck, p. 201; Honig, p. 195; Pop, p. 232 v.).

l'aulus necm Hom: "( God wat nic kan licg nie" (T'it. 1:2).

1 bie ander drice is: liedele, Jewe en ciees. 
Wal van ('od nitgaan, is net soos sy wese, suiwer waarheidl. 1) ie oorspronklike skcpping was 'n alspië̈ling van die waarheid van God waarvan Hysclf telkens gesô het dat dit goed is (Gen. 1:31).

Alam se taak in die paradys was nie allecn om God profet ies te ke'n nic maar ook om sy volmaakte skepping te deurvors en die ewige, suiwer gedagtes wat God daarin beliggaam het, te peil (Gen. 2:19, 20).

\section{DIE WAARHEID DEUR SATAN VERWOES}

1)ie ontstaan van die kwaarl het in dic engelewêreld plaasgevind (Judas : 6). Die wese van die kwaad staan in dic nouste verband met die leuen. Satan word nic vernie deur Cleristus "dic vader van die keuen" genoem nie (Joh. 8:44). Van hom geld inderdaad wat Jesaja (5:20) van die godelelose skrywe: "Hulle wat sleg gord nocm en goed sleg, wat die duisternis lig maak cn dic lig duisternis, wat biller soct maak en soet bilter."

Die grootste kunswerk van alle ecue, die Bybel, dank in 'n sekere sin sy ontstaan aan die lenens wat die Bose in die Paradys vertel hel. Na die kort skeppingsverhaal volg die verhaal van die sondeval en daamp die cintlike satak waroor dit in die hele Bybel gaan, die herskepping. 1 die essensie van die cenelange st rycl in die Bybel, die spanningselement, is rlie konllik lussen waarheid en leucn. Die gesprek Lussen Eva en clie stang in (lic paradys is'n sprekende illustrasie daarvan: "Is dil ook so dat God gesê loct ...?" (Gen. 3:1). Fin: "Julle sal gewis nie sterwe nie; maar (God weet dat as julle daarvan eet, julle oê sal oopgaan, sodat julle soos ( Gorl sal wers drur gocd en kwaad te ke'n" (Ge'l. 3:4, 5).

Van daardie dag af het God altyd die skyn 6 e'n Hom con her Satan die skyn in sy guns. As Cool 'n mens die ewige lewe wil gee, moet Hy loom ecers doormaak. As die Salan iemand wil doodmaak, belowe hy hom die ewige lewe.

In dieselfice trant het die versocking van Christus in die woest yn geskiedl. "As Urlie Seun van (iod is ... $\Lambda \mathrm{s}$ U my dan aanbicl ... $\Lambda$ s U die Seun van God is" (I, ık. 4:3, 7, 9).

() rigens speel Sat an vectal 'n aglergrondsrol in die openbaringsgeskiedenis. Hy geniet dit on incognito deur die wercld te gaan cu is in sy clement as die mensclom sy bestaan betwylet.

Die Byloel openbaar clat die leuen in die eindtyd in die ryk van dic $A n$ tichris tot 'n ontsettende sisteem sal uitgroei en 'n skrikwekkende klimaks sal 
bereik. Die dier wat uit die sec opkom, die Antichris (Openl). 13:5) leet 'n mond en spreck groot woorde en godslasieringe uit. Sy handlanger, die dier wat uit die aarde opkom, die Valse Prolect, het die horinkies van 'u lam, maar hy praat soos "n draak (Openb. 13:11). En hy verlei die bewoners van die aarde en sî aan hulle dat hulle 'n beckl van die Antichris moet maak wat praat (Openb. 13:14, 15). Wannecr die voleinding kom, word dic duiwel wat lulle verlei lue (()penb. 20: 10), "en al clie leuenaars" (()penb). 21:8) in die poel wat brand met vuur en swacl, gewerp. In die Nuwe. Jerusalem sal nie inkom "icts wat ... leuens doen nie" (Openb. 21:27).

\section{DIE WAARHEID IN GHRISTUS HERSTEL}

Ghrist us, dic Becld van die onsienlike God (Kol. 1:15) is die waarheid in cie persoon. Hy dien Homsell aan me die magtige aanspraak: "Ek is die wegen die waarheid en die lewe" (Joh. 14:6). Hy het na die wereld gekom om die waarheid te herstel. $\Lambda$ an rlie wat in Hom glo, brlowe Hy: "As julle in my woorde bly, is julle waatlik my dissipels. En julle sal die waarheid ken, en die waarbeid sal julle vrymak" (Joh. 8:3I, 32). Om licedic belofte na ie kom stuur Jesus na sy hemelvaart "die Gees van die waatheill" en Hy lei die gelowiges "in die hele waarhe de" (Joh. 16:13). In Choistus is alle belofies van Gorl ja cn amen (2 Kor. 1:20).

Die rël van dankbaarheid watrvolgens Christus sy gelowiges deur sy Heilige Gees na sy bectel wil vernuwe, is die negende gebod. In die outenticke verklaring wat die kerk van dic negende geborl gee, kom die volgenele voor: "dat ek alle lieg en bedrieg as die cie werke van die duiwel moret vermy, lensy dal ek die sware toorn van ( ek in die gereg en alle ander handelinge die watheid moet licfhe, opreg

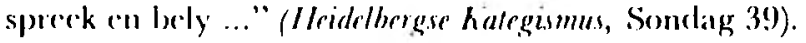

\section{DIE WESE VAN DIE WAARHEID}

In die filosolie is van oudsher driectlei aspek van die waarheid onderskei (Baviuk, II, p. 202).

Dic cerste is genocm die zeritas in essendo, meritas in rebus, ook bekend as dic metalisiese of ontologiese waarheid. Dit bestaan daarin dat 'in voorwerp), saak of persoon alan sy wese getrou is. Goud, byvoorbected, moet nie allecen die aksidensiële cicnskappe soos kleur en gewig vall goud liê nie, maat ook die essensiële cicnskappe (soos dic chemiesc bestandklele) wat aan goud cie is. Waarlecid in hicrelie sin staan teenoor valsheid, onegtheid, ydelheid, skynheiligheid. 
Veral Augustinus praat van die waarlıeid in hierdie sin. (Vgl. Bavinck, p. 202). Volgens hom is alle syn as sodanig waar en skoon en gord. Daar is wel verskeidenlicid in wat hy noem, die mate van die syn. Daar is graadonderskeid onder die skepscle. Maar alle dinge in die skepping het pro suo modo van God, die Volmaakte, hul syn ont vang en partisipeer aan dic syn van God. As Adam die diere name gec (Gen. 2:19, 20), dan peil hy die verilas in essendo, die ontologiese waarheid, wat God in elke dier vergestalt het.

Die twecde aspek van die waarheid is bekend as die veritas in cognoscendo, die veritas in intellectu, die veritas logica. Hier gaan dit om die ooreenstemming tussen die menslike denke en die werklikheid. Die menslike begrip is alleen waar as dit ' $n$ afspië̈ling van die werkliklıeid is. In hierdie sin staan die waarheid teenoor dic dwaling, die vergissing.

By God, wie se wese lig is ( 1 Joh. 1:5), kan daar geen dwaling of vergissing wees nic omdat Hy van ewigheid tot ewigheid sy cie Wese en ook dic wese van alle skepsele deurskou. Hy is sell die absolute ontologiese waarheid, en sy kennis in intellectu van dic ontologiese waarheid is alssoluut. Die taak van die kuns en ook van alle wetenskapsbeocfening, elk op sy eic manier, is om dic ewige gedagtes van God wat Hy in die skepping vergestalt het, na te vors, te deurdink, en daaraan in verskillende inedia gestalte te gec. So het Adam inturticf met die veritas in cognoscendo die wese van die diere gepeil.

Dic derde aspek van die waarheid is dic ueritas in significando, veritas in verbis, die rentas ethica. Hier gaan dit om die kotrekte wecrgawe van dic werklikheid in woord en daad. Nadat die mens suiwer waargeneem cu logies besin het, moet hy ook korrek rekenskap gee. 'lecnoor hicrdie etiese waarheid staan die leuen. 'Toe $\Lambda$ dam die diere name gegee het, het hy name gekies wat met hul wese ooreengekom het.

'Thiclicke (p. 50) het interessante opmerkings in verband met die etiese waarheid gemaak. Volgens hom is die cliese waatheid dikwels situatiel. Wat moct vall die suiwer waarneming en die logiese besinning word wanneer 'n vrou wat aan haar hart ly en wic se seun pas in 'n motorongeluk dood is, na sy welstand vernecm? Wie hier ter wille van die negende gebod die waarheid praat, mag die dood van dic moeder op sy kerfstok hê - oortreding van die sesdc geibod!

Voorts is Thiclicke (p. 50) van oordecl dat daar veclal 'n relasie tussen die persoon en dic waarheid is. Volgens hom het Faust aan die cinde van die lewe verklaar: "Nou weel ek dat ons niks kan weet nie." In die mond van 'n sterwende ou man wat alle dinge 'n lewe lank beproef het, is die stelling die waarheid. In die mond van 'n cerstejaarstudent aan die einde van 'n jaar 
van loodswaaiery is dieselfde stelling 'n blatante leuen. 'n Lewenswaar spreckwoord vol lewenswysheid word 'n leuen in dic mond van 'n dwaas.

Iets sonderlings het met Kajalas gebeur (Joh. 11:49-52):

Twee lyne het dić dag gekruis.

Dis beter so, het hy gemotiveer,

dat een man vir die volk moet sterf

en nic die hele nasic omkom

as die hand van Rome straks

ons vryheidsvure in ons cie bloed kom blus.

Met nugter staatsmanswysheid het hy staks

sy standpunt en beleid geformuleer.

Net oor hy dić jaar hoc̈priester was,

het God op hierdie woord beslag gelê

- dat cen man vir die volk moct sterf -

dit met die bittersoct meerduidigheid deurstroom

van helse haat en hemelse bedocling,

dit tot die kwintessens gemaak

van sy verlossingsplan

Waarom het God, wat nie kan lieg nie,

dic witste waarheid ingeklec

in die gedaante van die swartste leuen?

Twec lyne het mekaar dié dag gekruis.

Dic een was vertikaal,

dic ander infernaal.

Die kruispunt was

dic hart van Kajafas.

\section{DIE WESE VAN DIE LEUEN}

In die lig wat hierbo oor die wese van die waarhcid gesê is, is dic wese van dic leuen dat die dric elemente van onegtheid, dwaling en verdraaiing van die waarheid in mindere of meerdere mate daarin teenwoordig is. Die leuen is: falsilas in essendo, falsitas logica, falsitas ethica (Impeta, p. 668). Veral laasgenoemde, dic etiesc leuen, verdien aandag. Dit kan in 'n eindelose reeks moontlikhede voorkom, so ryklik geskakeer as die lewe self: die verswyging van dic waarheid of ' $n$ deel daarvan, die halwe waarheid, die skeef geaksentuecrde waarheid, die vermenging van waarheid en leuen, die opsetlike verdoeseling of verdagmaking van die waarheid, die doclbewuste leuen. 


\section{DIE SOORTE LEUENS}

Gewoonlik word drie soorte leucns onderskei (Geesink, p. 438).

\subsection{Die opsetlike, bose leuen}

Ook bekend as die mendacium perniciosum. Hierby is die bedoeling om in jou eie vermeende belang en tot skade van 'n ander die waarheid bewustelik te verdraai of in die plek daarvan 'n opsetlike valse voorstelling van sake te gee. Dat hierdie soort leuen oneties is, behoef geen verdere betoog nie.

\subsection{Die noodleuen}

In Latyn staan dit bekend as die mendacium officiosum. Veral in oorlogstyd is die wit leuen dikwels aan die orde van die dag. Dan word dit krygslis genoem. Skynoffensiewe, hinderlae, kamoeflage is almal vorme van noodleuens - nie in woorde nie maar in dade (Wissel, p. 24).

In die geskiedenis van die letterkunde is daar 'n klassieke voorbecld van die noodleuen. Die Duitse digter Theodor Storm het maagkanker gekry. Toe sy geneesheer hom die waarheid vertel, het Storm heeltemal incengestort. Sy broer, wat ook 'n genceshicer was, het met twec kollegas saamgesweer om die situasic te probeer "red". Nadat laasgenoemde twee Theodor ondersoek het, het hulle hom verseker dat hy nic kanker het nie maar slegs 'n ligte maagaandoening het. Storm het oombliklik soveel beter gevoel dat hy dadelik weer met oorga we begin werk het en "Der Schimmelreiter" voltooi het. Danksy die wit leuen van twee geneeshere besit die wêreld hierdie pragtige kunswerk. Storm is kort na die voltooiing daarvan aan maagkanker dood. Miskien het Luther hicrdie soort noodleuen in gedagte gehad toe hy gesê het: 'n goeie, flink leuen is veel beter as 'n lamsakkige waarheid. Fichte het anders gcoordeel. Volgens hom is 'n leuen altyd sellmoord van die siel (Vgl. Heim, p. 133).

Daar is 'n merkwaardige aantal noodleuens in die Bybel. $\Lambda$ braham (Gen. 12:11-20), Isak (Gen. 26:7), Jakob (Gen. 27), Sifra en Pua (Ex. J:19, 20), Ragab (Rigt. 2:4-6), Jael (Rigt. 4: 18), die vrou in Bahurim (2 Sam. 17:20) het hulle almal aan wit leuens skuldig gemaak. Die Skrif sê niks negatiefs van hulle nie. Inteendecl, aan Sifra en Pua het God weldadigheid bewys, Ragab word selfs onder die geloolshelde genoem (Hebr. 11:31). Deur die eeue heen was etici verdeel oor die vraag of 'n noodleuen sonde is (Geesink, p. 439, 440). Daar is seker ook noodleuens én noodleuens!

Die noodleuen dui dikwels op 'n botsing van pligte - 'n hoogs interessante 
etiese vraagstuk waarop hier nou nic verder ingegaan kan word nie (Vgl. Buys: 1976).

\subsection{Die skertsleuen}

In Latyn bekend as mendacium iocosum. Dis 'n speclse leuen wat nie bedoel is om geglo te word nie omdat dit nie 'n korrekte wecrgawe van dic werklikheid wil wees nie. Die doel daarvan is om die mense te vermaak. Dic misbruik daarvan kan natuurlik oneties wees. Die Spreukedigter (26: 18, 19) waarsku daartecn: "Soos cen wat onverskillig vuurpyle, dodclike pyle, afskiet, so is die man wat sy naaste bedrieg en sê: Ek speel sommer."

Maar die ınisbruik van die skertsleuen hef nie dic goeie gebruik daarvan op nic. Niemand minder nie as.Jesus Christus het in die gelykenisse wat $\mathrm{Hy}$ vertel het, van die skertsleuen gebruik gemaak. Daar was nie regtig 'n saaier wie se saad op die vier verskillende plekke geval het nie. Daar was nie regtig 'n seun wat sy vaderhuis verlaat, sy goed deurgebring en weer terug gekom het nie. Dit is verhale wat Jesus versin het. Hulle is wel lewensgetrou maar is nie ' $n$ korrekte weergawe van historiese feite nie. Dic doel van dic gelykenisse is om ecn of ander waarheid tuis te bring. Aardse verhale dus, met 'n hemelse strekking. Verhale wat in die tyd alspecl mar ewigheidsbeteken is het. Enkcle van sy gelykenisse is allegorieë. Dic woord "allegorie" sê dit pragtig: om iets anders te sê. (Grieks: allê gorein; Vgl. Souter, p. 13).

Die gelykenisse bevat dus 'n interessante mengsel van waarheid en verdigsel. Die waarheid word in die gedaante van die skertsleuen aangedien.

\section{WAARHEID, LEUEN EN DIE WOORDKUNS}

Is dit wat in die gelykenisse van Christ us gebeur, nie een van die belangrikste aspekte van die woordkuns nie? By dic kuns gaan dit, net soos in clie wetenskap, om die waarheid. Maar daar is 'n groot verskil. Die wetenskap wil langs diskursiewe weg tot 'n gesistematiseerde, eksaktc weergawe van dic ware feite kom. Die versameling, rangskikking en interpretasie van feite dis wat die wetenskap doen. Dic kuns gaan heeltemal anders te werk. In die spel van die fantasie word nuwe wêrelde opgetower wat minder of mecr lewensgetrou mag wees, maar wat nie noodwendig op historiese feite berus nie. En dan word lewenswyshede, lewenswathede wat vir alle mense en alle: tye geld, soos Christus dit gedoen het, dikwels in skertsleuens vergestalt.

So word in die kuns die skertsleuen diensbaar gemaak om in 'n wêreld waarin waarheid en leuen in ' $n$ worsteling om lewe en dood gewikkel is, universele lewenswaarhede gestalte te gec. 
Of om dit negatief te sê: Woordkuns waarin die waarheid geheel en al ontbreek, is oneg, onoortuigend en leuenagtig. Dit sal die toets van die tyd nie deurstaan nie. Want, al loop die leuen nog so snel, die waarheid agterhaal hom wel.

\section{SAMEVATTING}

Uit die voorgaande het dit geblyk dat die waarheid 'n goddelike gegewe is en dat die leuen met die Bose wesenseen is. In hierdie geválle, gebroke skepping is waarheid en leuen in 'n eeuelange stryd om lewe en dood gewikkel. Ter wille van die herstel van die waarheid het Chrisius aan die kruis kom sterwe. Hy, wat self die Waarheid is, het in sy gelykenisse van die skertsleuen gebruik gemaak om ewige waarhede in die gedaante van verdigte verhaaltijes wat in die tyd afspeel, tuis te bring.

Die woordkuns groei uit 'n werklikheid waarin waarheid en leuen verstrengel lê. As die kuns lewenseg moet wees, kan dit nie anders as om hicrdic gebroke werklikheid te weerspieël nie. Die kunstenaar, en veral die kunstenaar wat 'n Christen is, wil tot dic waarheid deurdring. In hierdie strewe giet hy die waarheid soms in die vorm van die skertsleuen. Of, om die woorde van Henriette Grové af te sluit: "Wat baat dit my om die waarhcid te wil, al is dit hartstogtelik en obsessioncel. Ek is te armsorg afhanklik van woorde ... 'n verkleurmannetjie wat gedurig sy voorkoms wissel volgens sy omgewing" (p. 71).

\section{BIBLIOGRAFIE}

BAVINCK, H. 1908. Gereformeerde Dogmatiek, II, Kampen: Kok.

BUYS, P.W. 1976. Dic botsing van pligte as etiese vraagstuk. Wetenskaplike bydraes van die PU vir CHO. Reeks H: Inougurele redes nr. 33.

GEESINK, W. 1931. Gereformecrde Ethick. Voor den druk gereed gemaakt door Hepp, V. Kampen: Kok.

DAVIDSON, B. s.j. The analytical Hebrew and Chaldee Lexicon. London: Bagster.

GROVÉ, Henriette. Die kêrel van die Pêrel of Anatomic van 'n leuenaar. Drie vertellings. Kaapstad: Tafelberg.

HEIM, K. 1955. Dic Christliche Ethik. Thübingen: Katzmann.

H( NIG, A.G. 1938. Handboek van die Gereformeerde dogmatiek. Kampen, Kok.

IMPETA, C.N. s.j. Liegen (In Christelijke encyclopacdie voor het Nederlandsche volk. Onder redaksie van Groshcide, F.W. e.a. Kampen: Kok).

LION-CACHET, J. 1907. Sewe duiwels en wat hulle gedoen het. Sketse uit 
die Afrikaanse buitelewc. Tweede druk. Potchefstroom: Het Westen. POP, F.J. 1957. Bijbelse woorden en hun geheim. 's Gravenhage: Bockencentrum.

SOUTER, A. 1956. A Pocket lexicon to the Greek New Testament. Oxford: Clarendon.

THIELICKE, H. 1968. Theological Ethics, I. Translated from the German by Doberstein, J.W. London: Adam \& Charles Black.

WISSEL, A. 1947. Wat is waarheid? Gereformeerd Weekblad. Jrg. I11, nr. 3. Vrydag, 18 Julie. 